\title{
EXPERIMENTAL AND NUMERICAL ANALYSIS OF ELECTRONICS HEAT SINK
}

\author{
Ahmad F. Ismail*, Mirghani I. AhMed, ANd Yousif A. Abakr \\ Department of Mechanical Engineering, Faculty of Engineering, IIUM, 53100, Kuala Lumpur, \\ Malaysia. \\ e-mail:faris@iiu.edu.my
}

\begin{abstract}
Cooling of electronic components continues to attract many research and development activities towards achieving an effective way of cooling. Computational fluid dynamics (CFD) tools may be considered as a cheap substitute for expensive experimental testing methods. In this work the cooling of a simulated electronic board was modeled using FLUENT ${ }^{\mathrm{TM}}$ CFD software, and experimental procedures were followed to validate the estimated results, and to understand the factors that would affect the software capability to predict the actual measured values. Results showed good agreement between the simulation and experimental results. The software was found to be capable to predict the exact values at the locations where the temperature values were similar to the board mean temperature. The maximum percentage error was found to be limited to $4.7 \%$, and the capability of the software to estimate the exact measured values was found to be affected by the function of thermal wake generation.
\end{abstract}

Keywords: CFD, Electronic cooling, Heat sink, Simulation.

\section{INTRODUCTION}

The progressive decrease of electronics device sizes and the higher processing rates resulted in an increasing rate of heat generation per unit surface area, which means increased cooling requirements. The possibility of electronic equipment failure increases with the increase of temperature. High thermal stresses resulting from temperature variations in the solder joints of electronic components mounted on circuit boards are major causes of failure. Figure 1 shows the increasing rate of failure as the junction temperature increases. Therefore, cooling has become increasingly important in the design and operation of electronic equipment. Air-cooled forced convection cooling is the most used technique. Fan speed control offers numerous benefits including reduced noise, low energy consumption and extended operating life of the fan.

The need of cooling of electronic components was known since Thomas Edison discovered the vacuum diode in 1883. The new era of electronics started in 1958 by the invention of the silicon integrated circuit (IC). Integrated circuits contain several

* Author for correspondence 
components such as diodes, transistors, resistors, and capacitors in a single chip. The number of components per chip has been increasing steadily. Electronic component suppliers estimate that for every $10{ }^{\circ} \mathrm{C}$ rise of junction temperature, the device failure rate doubles [1]. When a device exceeds the maximum temperature, the semiconductor performance, life and reliability are tremendously reduced. Therefore, enhancing the heat transfer rate from electronic devices became a very important research issue.

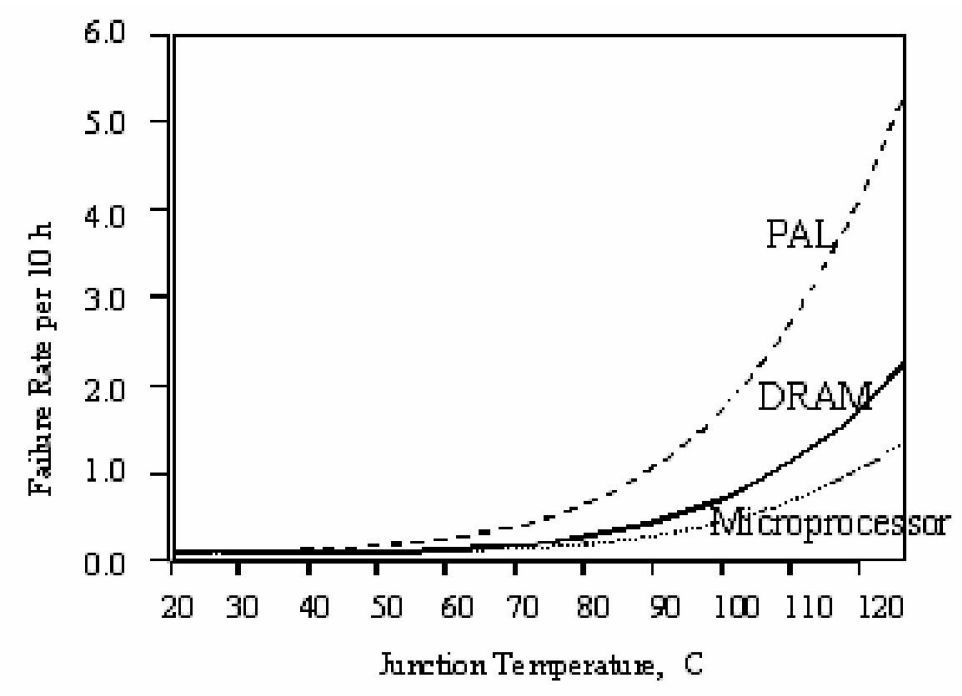

Fig. 1: The relation between the junction temperature and the failure rate.[1]

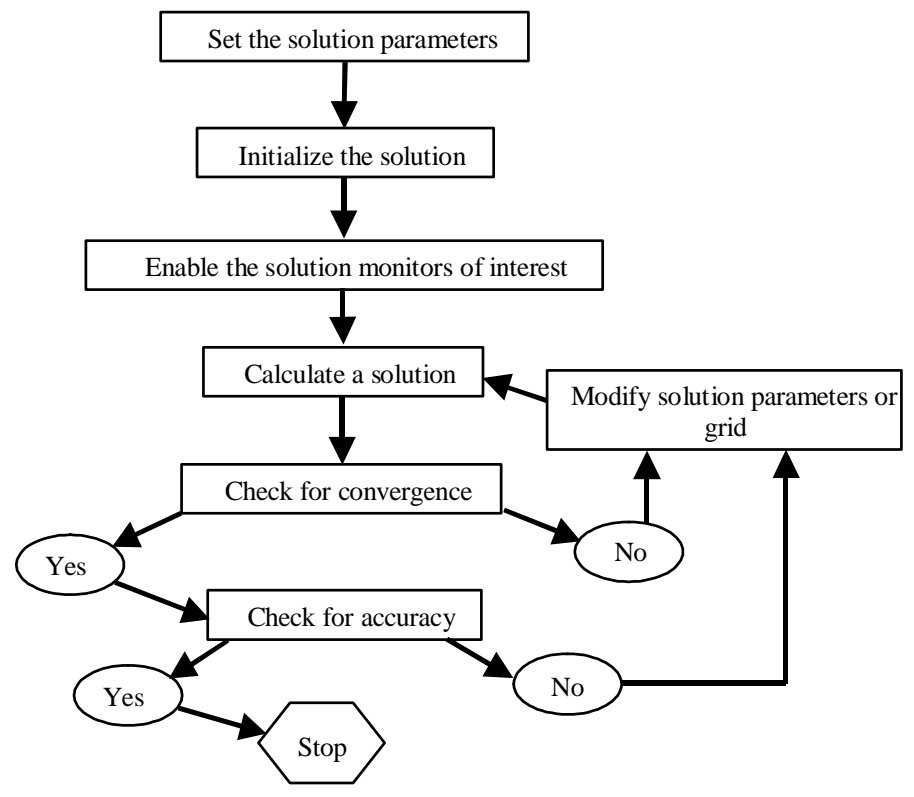

Fig. 2: Flow chart for solution procedure. 
Studies of the cooling of electronic devices are based on the fluid flow around obstacles mounted on a wall base, on which the phenomenon of mixed convection is observed around the localized heat sources. Many numerical and experimental studies were conducted previously [2].

Heat transfer and flow characteristics of four heat source locations were studied by Kennedy and Zebib [3]. Studies by Kang et al. [4] found that heat transfer can be improved significantly by buoyancy-driven secondary flow. But the effect of thermal wake generation was not fully understood because of use of a single heat source. Numerical study of the unsteady and transitional characteristics of mixed convection of airflow in a channel was conducted by Huang and Lin [5]. Kerki et al. [6] showed the significant effect of the thermal boundary flow pattern on the secondary flow pattern and on the heat flow distribution over the surface. Effects of the varying duct dimensions and obstruction dimensions on the convection from the surface of the heat generating obstructions to the airflow were studied experimentally by Leung et al. [7]. Choi and Kim [8] proposed a "modified 5\% deviation rule" to define the natural, mixed and forced convection regimes. Chin et al. [9] investigated experimentally the optimum spacing problem in mixed convection. Jubran and Al-Salaymeh [10] investigated experimentally the effects of using ribs to enhance the convective heat transfer.

In most of the previous work the thermal wake generation, and the actual effect of buoyancy driven secondary flow has not been studied thoroughly. The impact of the transitional characteristics of mixed convection on the accuracy of the numerically predicted results has not been investigated.

This paper will focus on the sensitivity of the CFD obtained results to the local conditions and try to define the parameters that will result in accurate estimations that approach the experimental results very closely.

\section{NUMERICAL MODELLING}

The steady state heat convection of the air moving from the electronic components is found by considering the heat generated by the chips, the heat conducted through the board and the heat radiated to the surroundings. Equation (1) shows the heat balance for a steady state condition,

$$
Q_{c}=Q_{t}-Q_{r}-Q_{l}
$$

Both the total amount of heat to be dissipated and the density of the air must be known. According to the first Law of Thermodynamics (Conservation of Energy) for a steady state and steady flow process, the total amount of heat dissipated in a system is determined as follows:

$$
Q_{t}{ }^{\circ} \mathrm{D} H+\mathrm{D} K E+\mathrm{D} P E
$$

FLUENT $^{\text {TM }}$ CFD software is based on the finite volume method. In this technique, the equations of motion are treated in balance form for finite sized control volumes (CV). Formal balance of a property transported with the fluid can be expressed by 


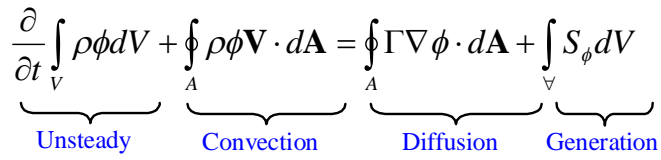

A 2D model was first constructed using GAMBIT software. The geometry was modeled with an appropriate number of nodes assigned to each line. The nodes for the modules and the board were set to 0.5 since more computational effort is needed in this region to gain good results. Finally the whole model was meshed using triangular element type. A total of 18983 nodes and 36467 elements were used to build up this model. The appropriate boundary conditions were set to the model. Fig. 3 shows the 2D model before and after meshing.

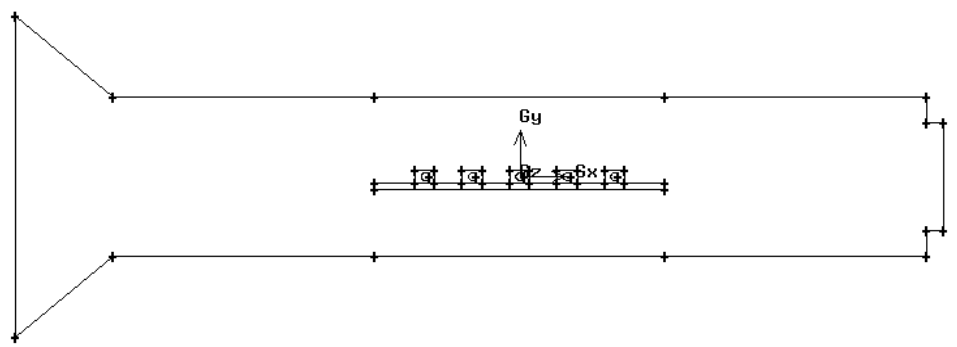

(a) Model before mesh.

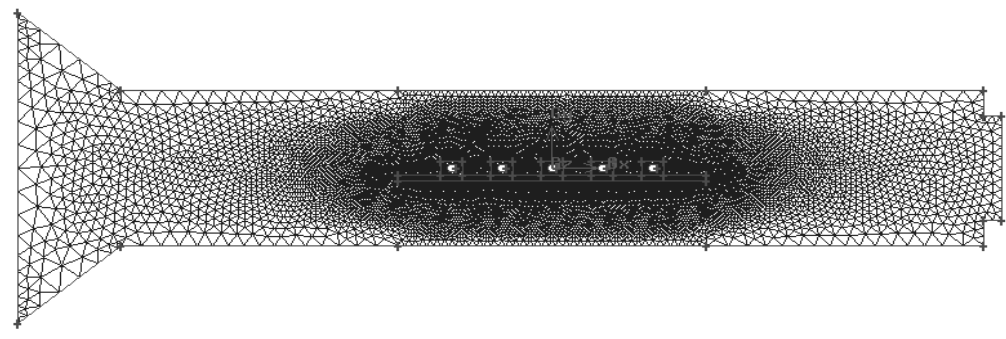

(b) Model after mesh.

Fig. 3: The 2-D Modeling and mesh generation.

Due to the large number of nodes for modeling in 3D space, only sub-region of the total test rig was modeled. The modules, the board and the zone above them were chosen for the purpose of modeling as shown in Fig. 4. A total of 43079 nodes and 185215 tetrahedral elements were used to build up this model.

Due to low air velocities involved, this problem has been considered as an incompressible flow. The segregated solver was selected for both cases. The maximum Reynolds number based on the modules length is 1418 , which mean laminar flow. The option to solve the energy equation was enabled because there is heat-generation. The property of the air was set to the default values. Properties of aluminum block and the hard board were set according to the values used for heat transfer analysis. Using a computer of Pentium II processor with a speed of $266 \mathrm{MHz}$, The program takes about two hours to finish the calculations. Graphical residual plotting is shown in Fig. 5, which shows the progress of the solution to convergence. 


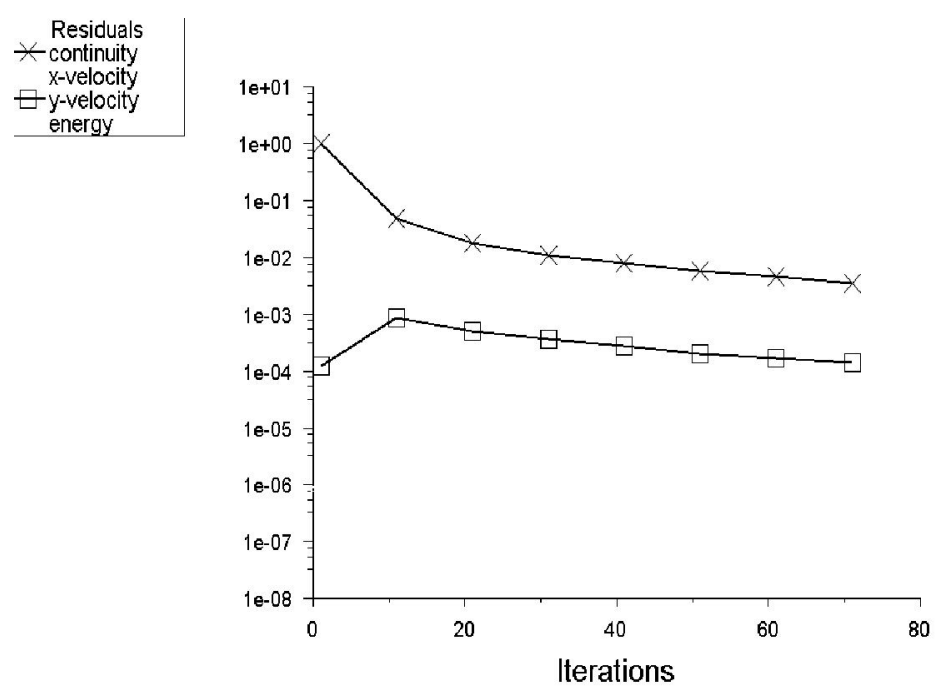

Fig. 5: Residual plotting for convergence.

\section{EXPERIMENTAL SETUP}

The experimental apparatus is made of a wind tunnel of a rectangular section with a dummy electronic components mounted on a circuit board. Electric heating elements were imbedded inside the dummy electronic components, and sets of thermocouples were used to read the surface temperature of the components. The setup arrangement is shown in Fig. 6. Isometric view of the test rig is shown in Fig. 7.

The setup consists of the test rig, DC power supply for electronic modules, brushless blower and a number of digital thermocouples. The design and the coordination assignments for the modules were constructed as in Fig. 7. The test rig shown in Fig. 8 is divided into eight zones of airflow impedance. The zones are numbered sequentially, following the direction of airflow.

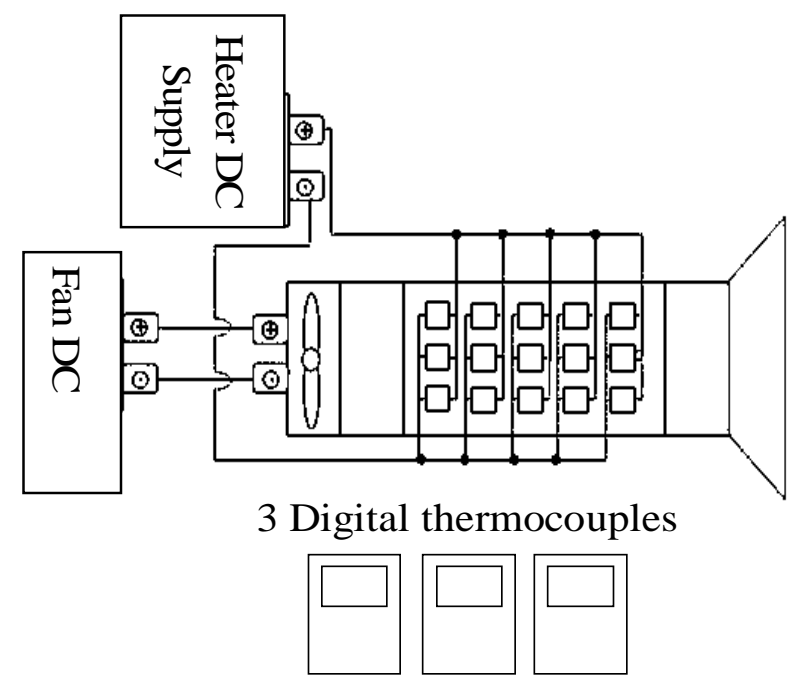

Fig. 6: Experimental setup. 


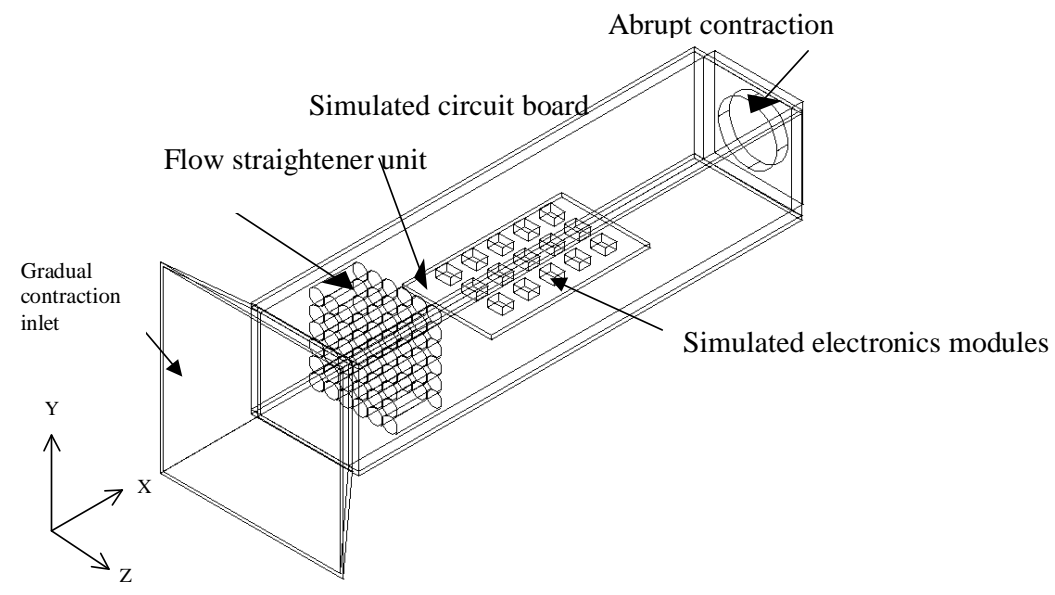

Fig. 7: Isometric view of the test rig and its components.

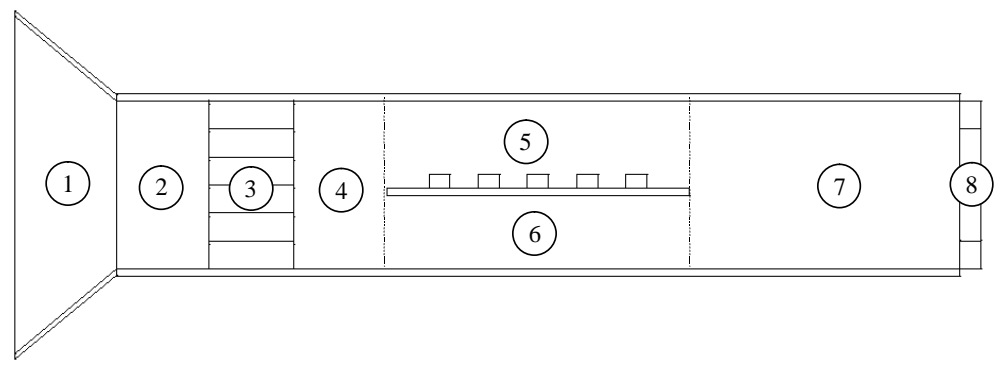

Fig. 8: Side view of the test rig.

Temperature measurements were taken only for the modules of row one, three and five. Temperatures of the modules in row two and four were approximated from the corresponding column. This procedure will be followed in the heat transfer analysis part. The heat transfer coefficient for each module was calculated from,

$$
h=\frac{q}{A_{s}\left(T_{a c}-T_{r e f}\right)}
$$

The temperature of the modules closer to the air exit is affected by the thermal wake phenomenon. The thermal wake happens when heat-generating components are placed along the flow stream direction. This function is defined as,

$$
q_{i}=\frac{T_{i}-T_{r e f}}{T_{a c}-T_{r e f}}
$$

The volumetric maximum flow rate is taken as $11.810^{-3} \mathrm{~m}^{3} / \mathrm{s}$. This is the maximum flow rate of the blower that will be used in the test rig. Each zone in the test rig will be analyzed individually for cross-section area changes and head loss. Details of zone 5, which contains the simulated board, are shown in Fig. 9. 


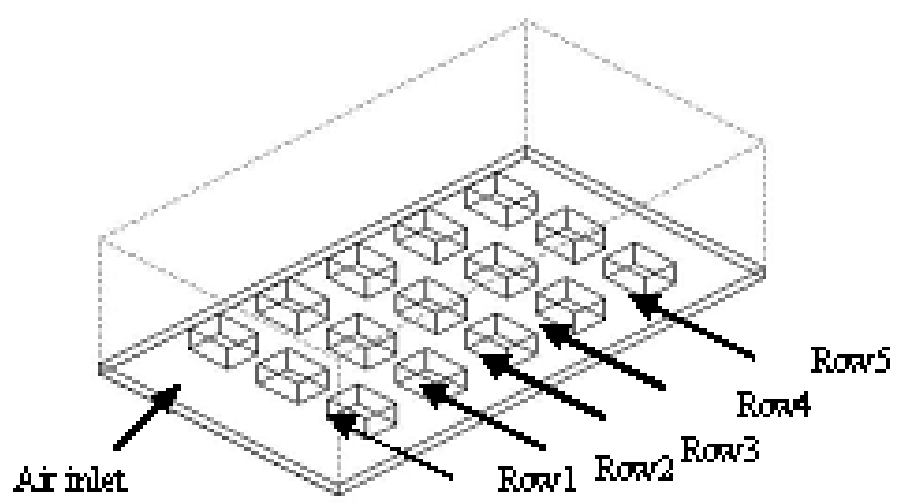

Fig. 9: Zone 5 (Isometric view).

\section{EXPERIMENTAL PROCEDURE}

Natural convection heat transfer measurements were taken while the fan power supply is kept off. After turning on the power supply of the heater, enough time was allowed for the system to reach steady state condition. When the steady state condition was achieved (modules temperature does not change with time), the local temperatures of the modules were then recorded. Similar procedure was then followed for the forced convection heat transfer measurements. Then, the fan power supply is turned on and set at 4 volts. At steady state condition the temperature measurements of the two modules were recorded.

Similar procedures were followed to repeat the test for the different fan speeds. Thermocouples were placed at different modules and test procedures were repeated again. A vane anemometer was placed at the exit of the blower to measure the air velocity for every set of applied fan speed. The system usually takes about 1 hour and 30 minutes to reach the steady state.

\section{RESULTS}

From the measured data it was noticed that the modules in the middle column have a higher temperature relative to the other two columns. Also the hottest module was the module at the middle of the board. This is mainly because of heat accumulated at the centre of the circuit board.

In Fig. 10 the average module surface temperatures were plotted at different positions along the board longitudinal axis. From this curve we can notice that the surface temperature is maximum at the middle of the board for the free convection condition. The position of the maximum surface temperature tends to change towards the direction of the exit as the air velocity increases.

Figure 11 shows the results of the variation of the modules surface temperature as the air speed is increased gradually. The curve is plotted for three different axial locations. 
At the free convection condition the modules temperature reaches values more than $80^{\circ} \mathrm{C}$, and when he air is forced to move at high velocities the temperature drops to less than $60^{\circ} \mathrm{C}$ for the first row.

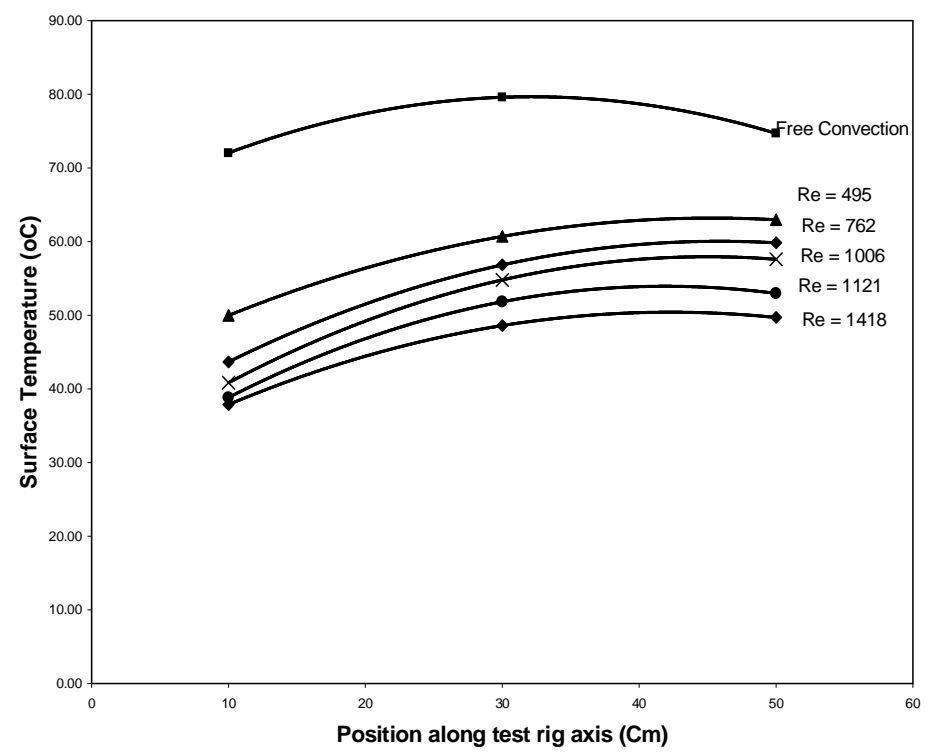

Fig. 10: Average modules surface temperature.

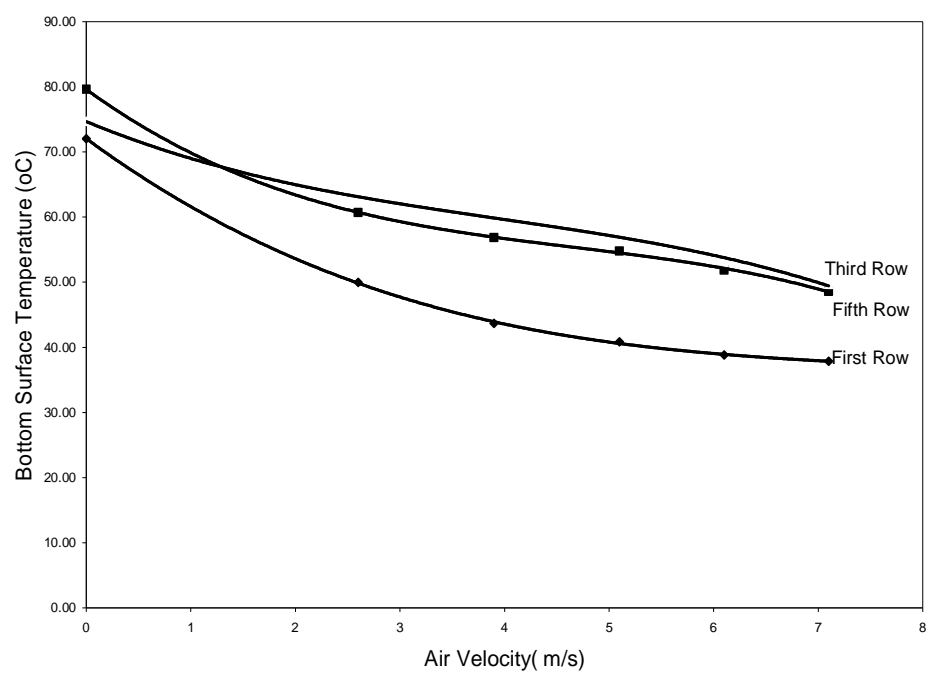

Fig. 11: Variation of the modules surface temperatures with air velocity.

Figure 12 shows the variation of local rate of heat removal by convection at different air velocities. From this figure we can see that as the air velocity exceeds a value of $4 \mathrm{~m} / \mathrm{s}$ the rate of heat removed becomes almost uniform all through the circuit board, while for low velocities it increases from the inlet position towards the exit. 


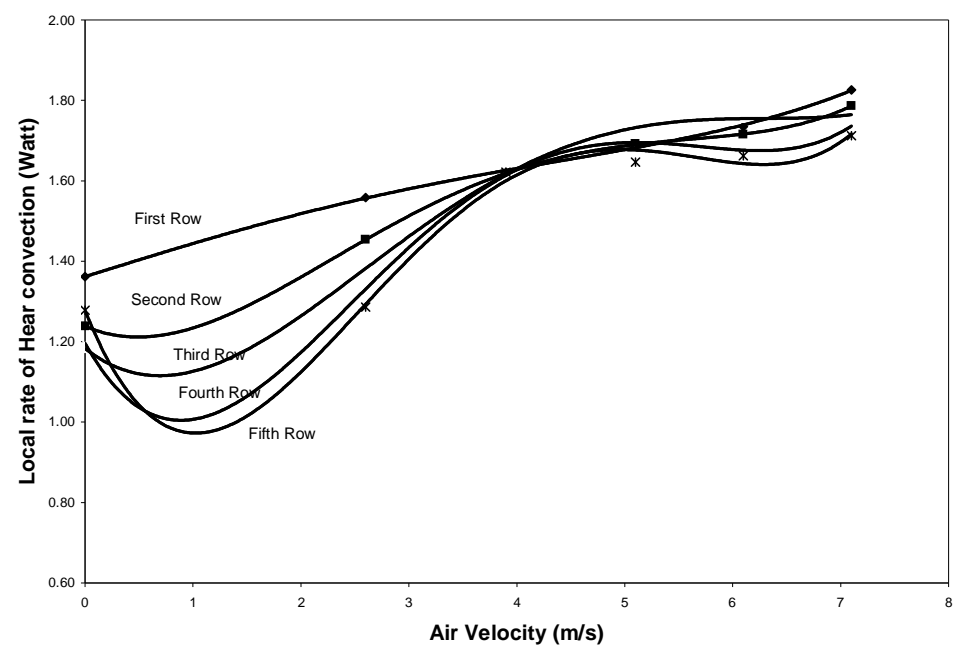

Fig. 12: Variation of local rate of heat convection with air velocity.

The percentage of the amount of heat removed by convection to the total amount of heat generated at the chip is shown on Fig. 13. It can be noticed from this figure that at different axial locations the maximum value is around $90 \%$ while the minimum is slightly below $60 \%$, which occurs at natural convection conditions.

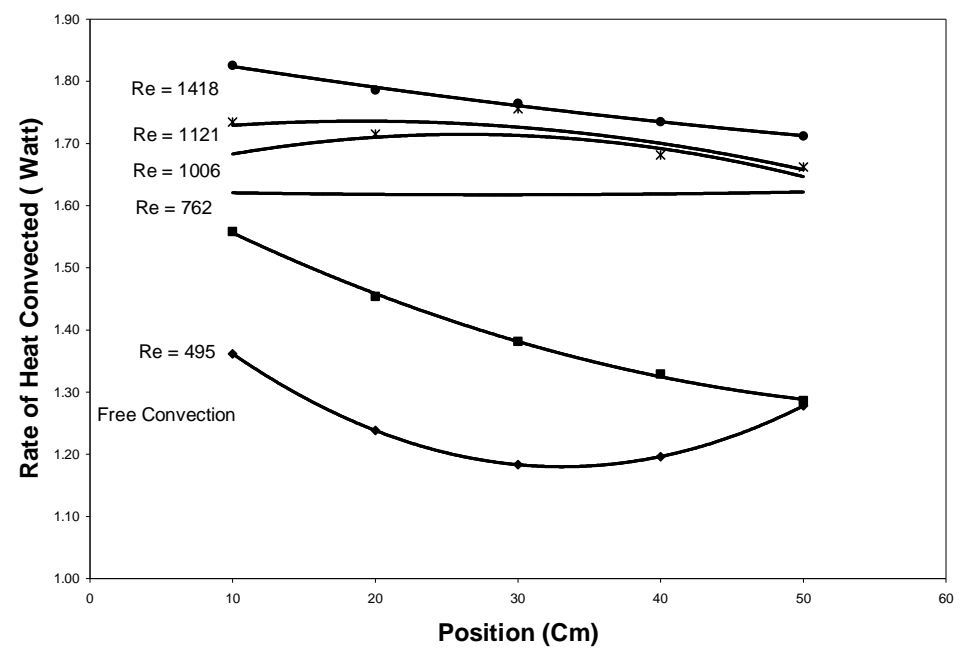

Fig. 13: Percentage of heat convected at different axial position.

The overall thermal wake generation correlation for different Reynolds number (ReL) is shown in Fig. 14. The thermal wake generation was found to be increasing at high constant rate up to the middle of the board, then the rate decreases and remains constant up to the end of the board regardless of the value of the Reynolds number. 


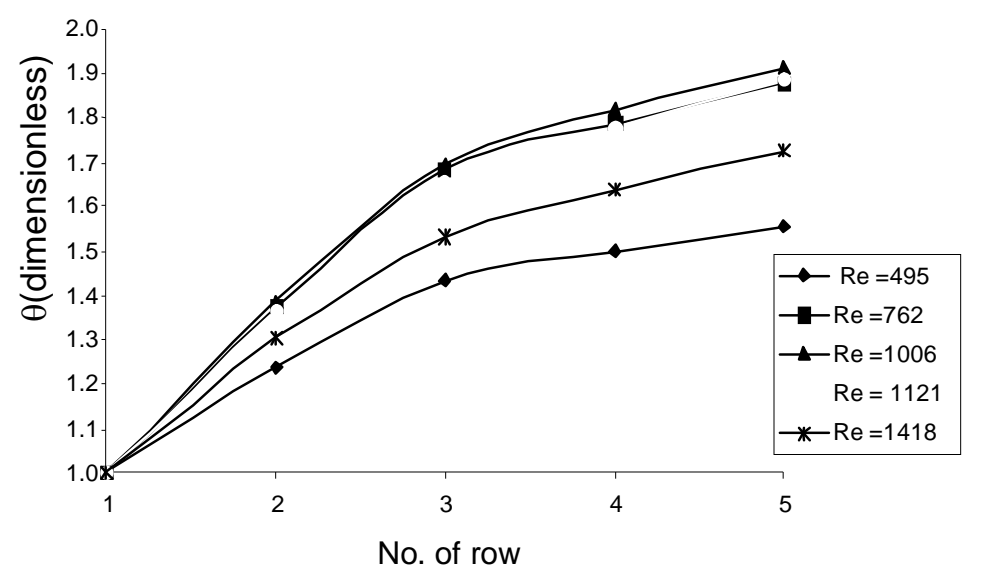

Fig. 14: Thermal wake generation function.

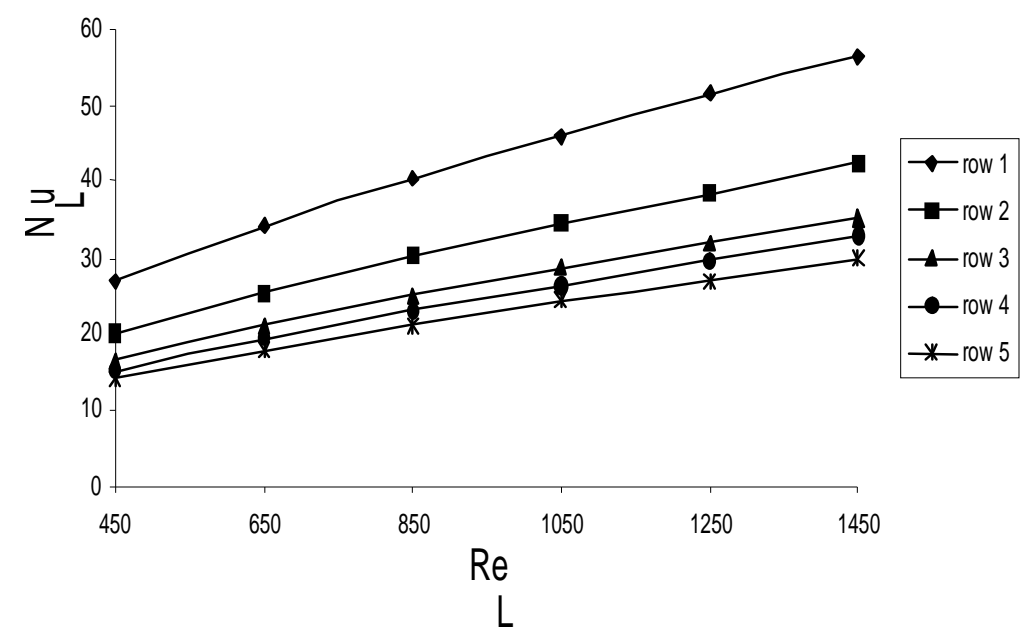

Fig. 15: Forced convection correlation (local).

It can generally be stated that the thermal wake generation function increases at the downstream region. Comparing the thermal wake generation correlation for each case, we can notice that, the thermal wake effect is high for high values of Reynolds number and vice versa.

According to the dimensionless correlated data shown in Fig. 15, the rate of cooling is highest near the air inlet position and decreases as it approaches the outlet. Modules in the first row experiences better cooling and as the row number increases the cooling efficiency reduces. The reduction of the cooling rate is caused partially by the thermal wake generation. 


\section{DISCUSSION}

The analysis and evaluation of the FLUENT ${ }^{\text {TM }}$ CFD simulation results revealed a very good agreement with the obtained experimental results. Comparison between the estimated and the actual modules surface temperatures is shown in Fig. 16 and Fig. 17 on which the estimated and the measured values are found to be very close.

The error in the estimated values was found to be related to the values of the Reynolds numbers and the axial position on the board. Lower values of Reynolds number were found to coincide with better estimates at locations near to the inlet. Larger values of Reynolds number were accompanied with better estimates of surface temperature at downstream regions. Figure 18 shows the variation of the percentage error values as Reynolds number increases.

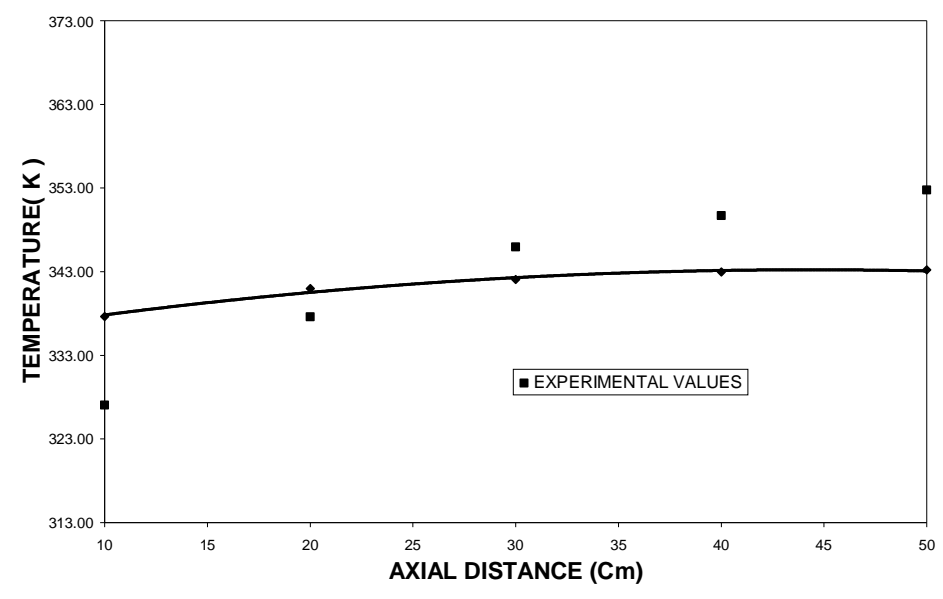

Fig. 16: Comparison between the CFD and the experimental results at $\mathrm{Re}=1006$.

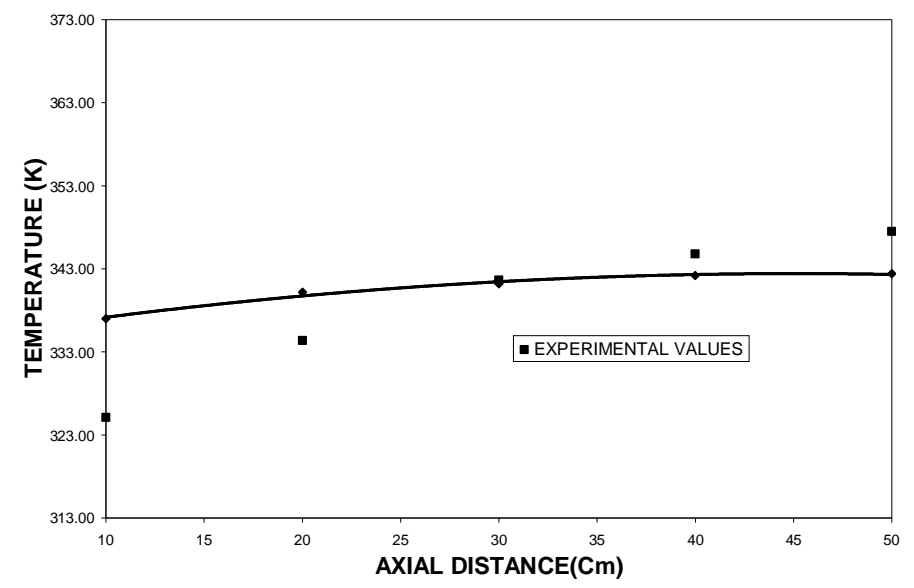

Fig. 17: Comparison between the CFD and the experimental results at $\operatorname{Re}=1211$. 


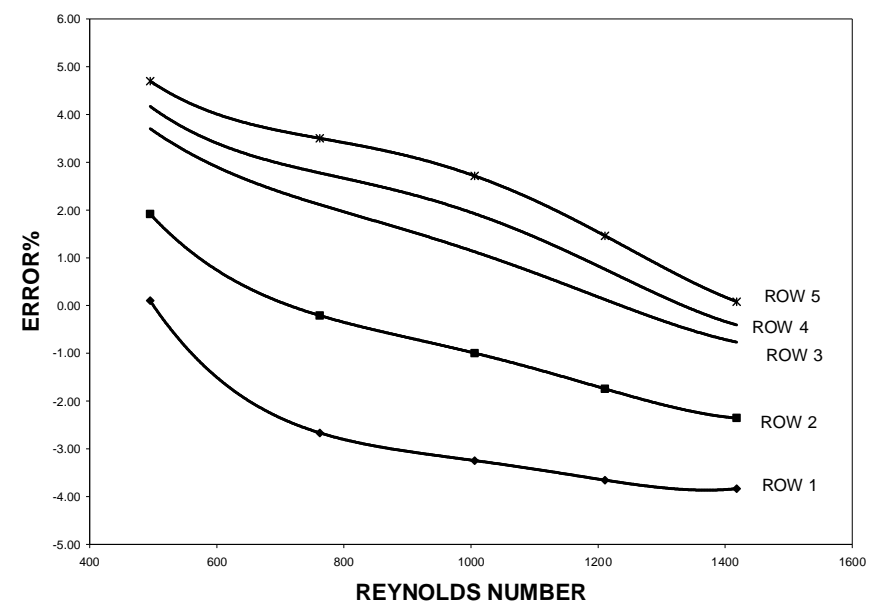

Fig. 18: Variation of the percentage error with Reynolds number

One of the interesting observations is the mode of change of the position at which the software estimated exactly the measured value of surface temperature. This position was noticed to change axially towards the downstream direction as Reynolds numbers increases. This phenomenon is illustrated in Fig. 19.

In addition to this fact, the modules surface temperatures that were estimated exactly by the software as the measured experimental values were found to be approximately equal to the average board temperature. Figure 20 shows the values of temperature at different positions when the CFD software succeeded to estimate exactly the measured values.

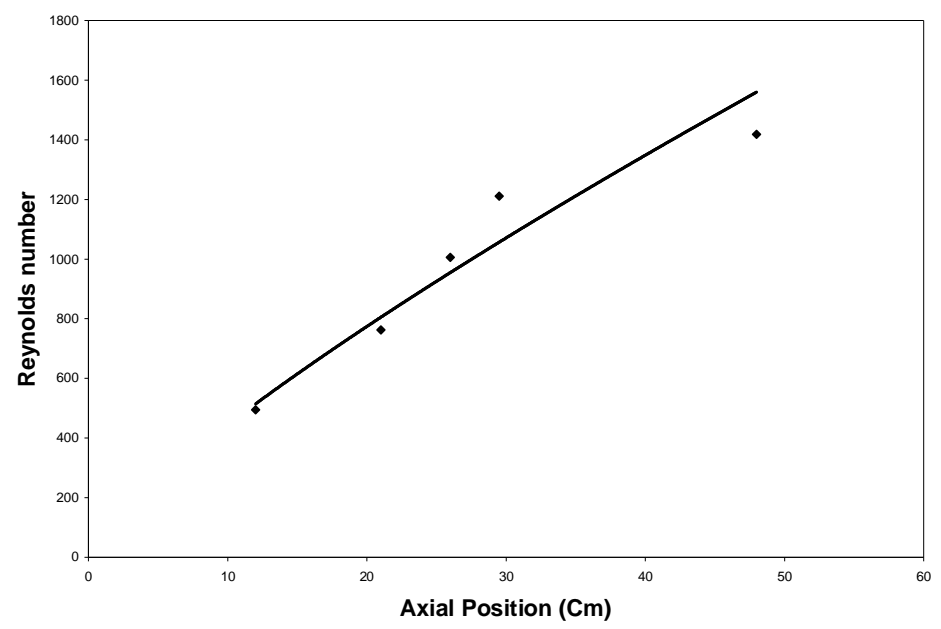

Fig. 19: Reynolds number at axial positions when the CFD software estimated the exact values of temperature.

When the comparison was made taking Reynolds number variation at fixed positions, the standard deviation was found to be increasing as Reynolds number increases to a maximum value of 800, then it start to decrease further. This is illustrated in Fig. 22. 


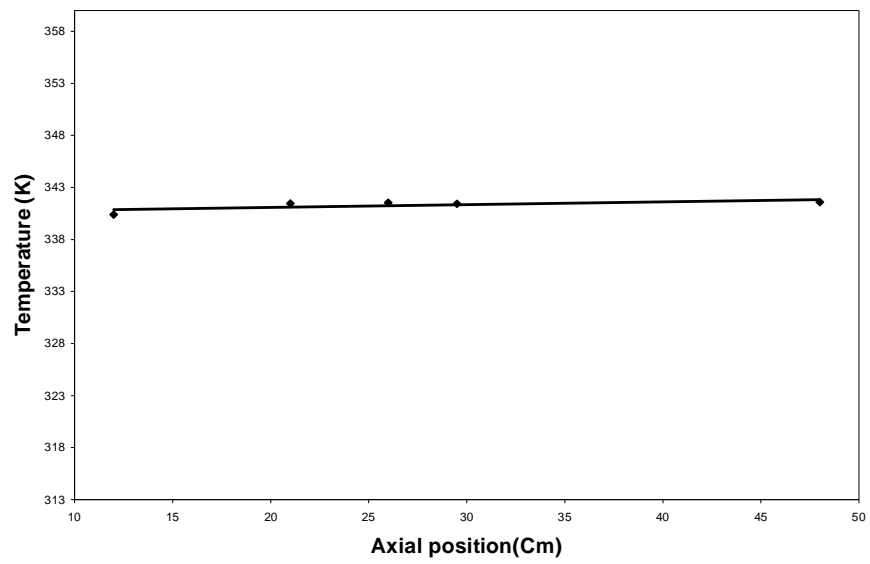

Fig. 20: Values of temperature at axial position at which CFD and experimental results were equal.

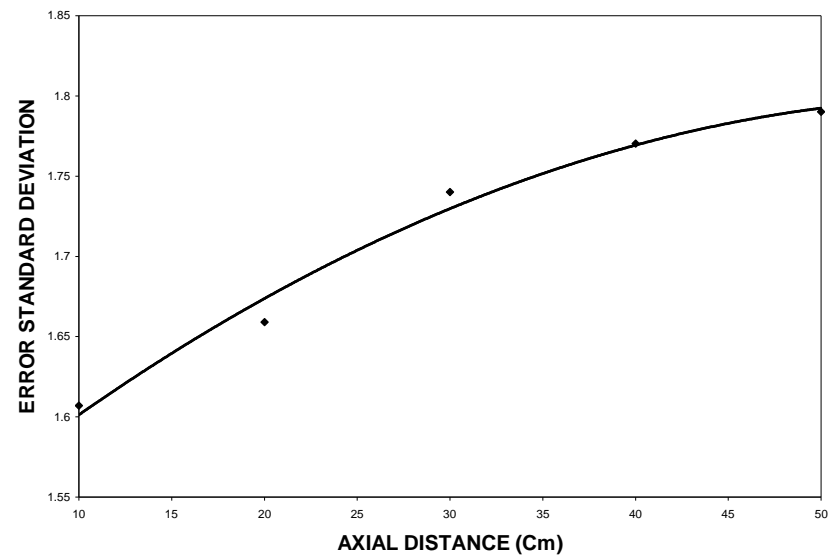

Fig. 21: Standard deviation of the error at different axial locations.

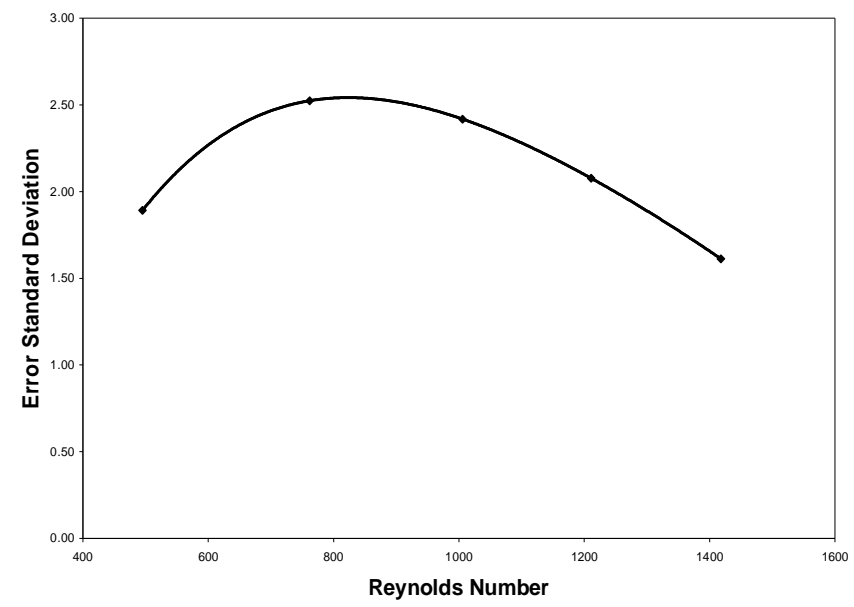

Fig. 22: Standard deviation of error at different Reynolds number values. 


\section{CONCLUSION}

This work shows a combination of CFD and experimental investigation of a heatgenerating matrix that simulates the behavior of an electronic circuit board. Initially the board was simulated using FLUENT ${ }^{\text {TM }}$ CFD software, then the simulation results were validated experimentally.

The estimated values of the surface temperature were found to be in good agreement with the actual measured values. The maximum percentage error was found to be $4.9 \%$, with a maximum standard deviation of 2.5 when considering different Reynolds number, for the entire plate, and 1.7 when considering the local error variations at same locations.

Values of Reynolds number, at which the software estimated exactly the measured values, were found to be increasing following the trend of thermal wake generation.

This phenomenon may be related partially to the instability of the thermal boundary layer when the thermal wake exceeds a certain value with respect to different Reynolds numbers.

The local surface temperatures, at which the software was able to predict exactly the measured values, were found to be always the same values. And they were generally noticed to be very close to the mean temperature of the board.

\section{ACKNOWLEDGEMENT}

The authors would like to thank IIUM for funding this project. The authors would like also to thank M. Farid M. Ismail and Hilmi F. Bachok for their assistance in fabricating the experimental setup and running the CFD simulation.

\section{REFERENCES}

[1] R. Remsburg, "Advanced Thermal Design of Electronic Equipment", International Thomson Publishing, 1998.

[2] F. P. Incropera, "Convection heat transfer in electronic equipment cooling", Journal of Heat Transfer, Vol. 110, pp. 1097-1111, 1988.

[3] K. J. Kennedy, A. Zebib, "combined free and forced convection between horizontal parallel plates: some case studies", International Journal of Heat and Mass Transfer, Vol. 26, pp. 471-474, 1990.

[4] B. H. Kang, Y. Jaluria, S. S. Tewari, "Mixed convection air cooling of an isolated rectangular heat source module on a horizontal plate", ASME Proceedings of Nat, Heat Transfer Conference, pp. 59-66,.

[5] C. C. Huang, T. F. Lin, "Buoyancy induced flow transition mixed convective flow of air through a bottom heated horizontal rectangular duct". International Journal of Heat and Mass Transfer, Vol. 37, pp. 1235-1255, 1994.

[6] K. C. Kerki, P. S. Sathyamurthy, S. V. Patankar, "Laminar mixed convection in a horizontal semicircular duct with axial nonuniform thermal boundary condition on the flat wall”, Numerical Heat Transfer: Part A, Vol. 25, pp.171-189, 1994. 
[7] C. W. Leung, H. J. Kang, "Convective heat from simulated air-cooled printed-circuit board assembly on horizontal or vertical orientation". International Comm. Heat and Mass Transfer, Vol. 25, pp. 67-80, 1998.

[8] C. Y. Choi, S. J. Kim, "Conjugate mixed convection in a channel: modified five- percent rule", International Journal of Heat and Mass Transfer, Vol. 39, pp. 1223-1234, 1996.

[9] S. Chin, Y. Liu, S. F. Chan, Leung CW, T. L. Chan, "Experimental study of optimum spacing problem in the cooling of simulated electronic package", Journal of Heat and Mass Transfer, Vol. 37, pp. 251-257, 2001.

[10] B. A. Jubran, A. S. Al-Salaymeh, "Heat transfer enhancement in electronic modules using ribs and (film-cooling-like) techniques", Journal of Heat and Fluid Flow, Vol. 17, pp. 148154, 1996.

\section{NOMENCLATURE}
A Area $\left(\mathrm{m}^{2}\right)$
$\mathrm{H}$ Coefficient of heat convection $\left(\mathrm{kW} / \mathrm{m}^{2} \mathrm{~K}\right)$
$\mathrm{S} \quad$ Heat generation term $(\mathrm{kJ})$
$\mathrm{T}_{\mathrm{ac}} \quad$ Modules actual temperature $(\mathrm{K})$
$\mathrm{T}_{\mathrm{i}} \quad$ Modules initial temperature $(\mathrm{K})$
$\mathrm{T}_{\text {ref }} \quad$ Reference temperature $(\mathrm{K})$
q Convective heat flow rate $(\mathrm{kW})$
$\mathrm{Q}_{\mathrm{c}} \quad$ Amount of heat convected by air (kJ)
$\mathrm{Q}_{1} \quad$ Amount of heat loss by conduction $(\mathrm{kJ})$
Qr Amount of heat loss by radiation $(\mathrm{kJ})$
$\mathrm{Q}_{\mathrm{t}} \quad$ Total heat generated by the chip $(\mathrm{kJ})$
V Volume $\left(\mathrm{m}^{3}\right)$
$\Delta \mathrm{H} \quad$ Change of total enthalpy $(\mathrm{kJ})$
$\Delta$ K.E Change of kinetic energy $(\mathrm{kJ})$
$\Delta$ P.E Change of potential energy $(\mathrm{kJ})$
$\Gamma \quad$ Species concentration $(\mathrm{kg} / \mathrm{kg})$
$\theta_{\mathrm{i}} \quad$ Thermal wake function
$\phi \quad$ General field parameter
$\rho \quad$ Density $\left(\mathrm{kg} / \mathrm{m}^{3}\right)$ 


\section{BIOGRAPHIES}

Ahmad F. Ismail was born in Kelantan, Malaysia in 1966. He received his B. Sc. degree in Chemical Engineering from the University of Houston, Texas in 1989, and a $\mathrm{PhD}$ degree from Rice University, Texas in 1993. He is currently an Associate Professor at the Department of Mechanical Engineering at the International Islamic University Malaysia (IIUM). Dr. Ismail's primary research interests are energy and environmental systems, computational fluid dynamics and heat transfer, combustion and pyrolysis, modeling and simulation, and digital image processing.

Mirghani I. Ahmed was born in Singa, Sudan in 1956. He received his M Sc. and PhD degree in Mechanical Engineering from the Budapest Technical University Hungary in 1987. From 1987 to 1989 he worked with the Sudan University of Science and Technology as Assistant Professor He later joined IBM - Canada as a Research Associate from 1989 to 1996. He is currently an Associate Professor at the Department of Mechanical Engineering at the International Islamic University Malaysia (IIUM). Dr. Ahmed's primary research interests are renewable energy, thermal comfort problems, electronic component cooling, modeling and simulation, computational fluid dynamics applications and heat transfer.

Yousif A. Abakr was born in Khartoum, Sudan in 1962. He received his B. Sc. degree in Mechanical Engineering and M.Sc. degree from the University of Khartoum in 1987 and 1995, respectively. He joined the Energy Research Council, Sudan as assistant researcher in 1987. He joined the Sudan University of Science and Technology as a lecturer in 1991. Currently, he is at the final stages of his PhD study at the International Islamic University, Malaysia. His primary research interest is the renewable energy applications, combustion, evaporation and condensation, and computational fluid dynamics applications. 